\title{
La política municipal de protección del patrimonio histórico
}

\author{
Fernando J. González Beviá \\ Arquitecto-autor del PEPRICCHA \\ Fernando Martín Sanjuán \\ Arquitecto-director del Departamento \\ de Casco Histórico
}

Ana Romo Salas

Arqueóloga

Sergio García Dils de la Vega

Arqueólogo

\section{Resumen:}

Análisis del Plan Especial de Protección, Reforma Interior y Catálogo del Conjunto Histórico Artístico de la ciudad de Écija y las intervenciones y actuaciones que se están realizando actualmente.

\section{Palabras Claves}

Plan especial / Écija / Patrimonio Histórico / Protección / Conservación / Actuaciones

\section{INTRODUCCIÓN}

El Plan Especial de Protección, Reforma Interior y Catálogo del Conjunto Histórico Artístico de la ciudad de Écija (PEPRICCHA), redactado por los Arquitectos Fernando J. González Beviá, Desiderio Sanjuán Martínez y José Ignacio Salcedo Gómez y el Arqueólogo Sergio García-Dils, intenta dar solución a la desactivación que el Casco Histórico de Écija viene manifestando, especialmente en la última década, y a la consiguiente situación de un proceso de obsolescencia que su arquitectura padece.

Plantea lo que en términos locales se ha denominado PROYECTO DE CIUDAD, que fundamentalmente consiste en la revitalización urbanística de su centro neurálgico, Casco Histórico, que en el caso de Écija afortunadamente aún coincide con el Centro Urbano.

Un Proyecto de Ciudad que sea la expresión democrática de lo que la Ciudad debe ser y al que referir y disciplinar las actuaciones individuales. Un Proyecto de Ciudad entendido como herramienta vinculada a la intervención en la Ciudad y en consecuencia un instrumento pragmático y operativo para desarrollar aquellos aspectos más significativos de la Ciudad y para afrontar los problemas más graves. Un
Proyecto de Ciudad que bajo el control social sea marco de referencia explícito para un proceso de concertación.

En los últimos años, en las áreas centrales de nuestras ciudades se han desarrollado modelos de carácter especulativo totalmente faltos de respeto con el patrimonio heredado y huérfanos de cualquier alternativa de construcción de ciudad que no fuera la obtención de la máxima plusvalía especulativa, o bien, y como respuesta a lo anterior, la aparición de modelos conservacionistas, reconocedores de lo existente como única alternativa y que con buenas intenciones sociales coadyuvaron con el tiempo a lastrar igualmente el modelo y las formas de una ciudad.

Hoy nuestros centros, aunque reconocedores de la importante herencia teórica y social dejadas por las formas y teorías de hacer conservacionistas, en lo que tienen de aparato analítico (morfológico y tipológico) e historicista, no pueden dejar de reconocer que, para nuestros días, esta apuesta es débil y carente de capacidad de poner en funcionamiento y recuperación los centros de nuestras ciudades.

Es por ello que la tendencia actual del quehacer urbanístico tiende cada vez más a intervenir de forma decidida en nuestros cascos históricos y conjuntos monumentales en la opinión de que no se puede conservar sin intervenir, es decir, sin dotarlos de capacidad de futuro y de bienestar.

EI PEPRICCHA respeta y mantiene los valores universalmente reconocidos de los conjuntos históricos, a la vez que reconoce la intervención en el centro de una ciudad viva, en expansión y crecimiento. Asimismo, propone la recuperación o reutilización, con un uso más adecuado, de determinados inmuebles de gran interés, catalogándolos.

La tardanza en reaccionar y tomar conciencia por el cuerpo social de la importancia de la conservación de los bienes culturales propios antes de su deterioro, genera la necesidad de contar con unas ideas claras que sirvan de base teórica a la intensificación de la intervención de las entidades públicas o privadas. Tales ideas deben difundirse entre los distintos estamentos sociales.

Hay que reivindicar los centros históricos, a veces sepultados por los efectos del crecimiento del sector servicios, para la convivencia habitual de los ciudadanos. De este modo se implicará al ciudadano en su cultura propia y en la conservación de sus bienes patrimoniales.

La conservación debe basarse en una nueva ética: no limitarse a los monumentos y fachadas, generan- 
do nuevas formas de especulación, sino abarcar en la protección a la ciudad existente entendida como una totalidad, un continuo urbano de edificios y ambientes exteriores.

Pero no sólo hay que rehabilitar los espacios urbanos y las edificaciones. Las directrices de intervención han de afectar a la estructura socio-económica, tanto del individuo como del conjunto social de cada comunidad, en un abanico de posibilidades que vaya desde mejorar la habitabilidad de las viviendas hasta fomentar la industria y el empleo. Embellecer exteriores sin crear las condiciones de higiene adecuadas es una solución que en el futuro llevará al desalojo del edificio y su consiguiente degradación por abandono. Y si no se incrementa el nivel de vida de la población, ninguna medida pública de mejora urbana pasará de ser una mera actuación particular, sin repercusión generalizada.

La reutilización de los espacios urbanos, para alcanzar el éxito, requiere una planificación anticipada y coordinada de los usos a implantar. La determinación de usos es fundamental también a la hora de reconstruir los edificios: la restauración debe ir acompañada de la restitución de los usos previos o de la implantación de usos nuevos adecuados.

Una idea básica es que conservar hoy es menos oneroso que rehabilitar mañana. En la actualidad, los datos estadísticos permiten afirmar que la conservación genera más puestos de trabajo en la construcción, mantiene las industrias artesanales y fomenta el turismo, con el potencial económico como fenómeno de masas que supone y con los consiguientes problemas sobre los Conjuntos Históricos que su propia dinámica implica.

Si la Carta de Ámsterdam de 1975 impulsa la concepción del monumento como bien cultural no aislado, sino incurso en su entorno, en un ambiente propio que ha de ser protegido en su conjunto, las actuales concepciones, más universales, hacen considerar que no son dos problemas diferentes la protección del patrimonio histórico y la protección de la naturaleza. Esta consideración es especialmente importante en los núcleos poblacionales como en el caso objeto de estudio.

El desbordamiento, que supone una ruptura con el medio urbano preexistente, tanto por las tramas urbanas que supone como por las tipologías edificatorias dispersas que introduce, tiene otra vertiente interior, en el propio tejido urbano tradicional, donde las actuaciones de sustitución edificatoria han iniciado un proceso de alteración de las relaciones de los espacios y de la calle con el caserío.

La normativa urbanística al uso, al plantearse la protección de los Conjuntos de interés, suele limitarse a medidas destinadas a evitar ese, que hemos denominado, desbordamiento interior, dando reglas para las actuaciones edificatorias y algunas veces para intervenciones en espacios públicos. Sin embargo, a

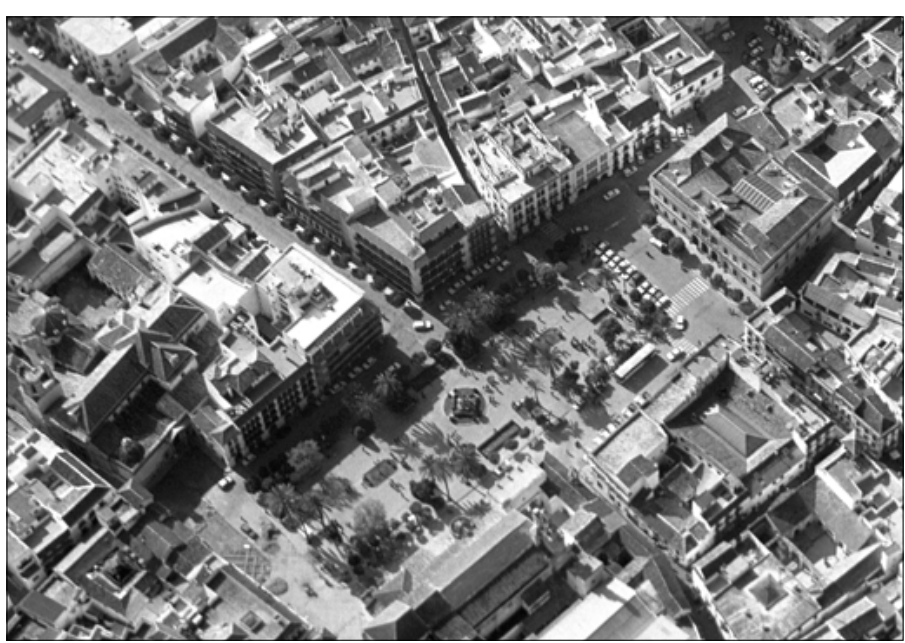

pesar de las consecuencias evidentes del desbordamiento exterior en el entorno inmediato, se da la paradoja de que se olvidan las medidas correctoras necesarias. Evidentemente un Plan Especial de Protección no puede alcanzar en su ámbito territorial a toda la Ciudad, pero debe extenderse a aquellas zonas que dan coherencia y efectividad a sus determinaciones.

Todas estas consideraciones están también en relación con la necesaria inclusión en el planeamiento de la mayoría de nuestros centros históricos de medidas de renovación y no simplemente de actuaciones de conservación. Si un casco histórico está vivo es porque ha podido renovarse a lo largo del tiempo. Y ese mismo proceso histórico es parte del legado que nos ha llegado. Congelarlo en una época no es una medida acertada en la mayoría de los casos, pues rara vez puede convertirse una ciudad en museo de sí misma. Por el contrario, dosificar medidas, cuidadosas con lo que debe conservarse, para permitir la evolución en los tiempos presentes es la mejor garantía de éxito.

Se desprende en este Plan Especial una intención de cirugía urbana unida a una revitalización de edificios, que unidas al conglomerado de viviendas tradicionales existentes en dicha área no son otra concepción que la de aquel memorable CIAM que se refería a la extensión de la vivienda a la ciudad complementándola con cuatro modalidades básicas: HABITAR, CIRCULAR, TRABAJAR Y DISTRAERSE.

El reto de los Conjuntos Históricos estriba en obtener el equilibrio al que se refiere el concepto de CIUDAD SOSTENIBLE; no se trata tanto de conservar sino de renovar y obtener de una trama antigua una trama nueva capaz de producir lo que consume, de reponer lo que se destruye y de limpiar lo que ensucia.

Respecto al Patrimonio Histórico se propone en lugar de un planeamiento básicamente defensivo, por la alternativa de una auténtica recuperación del patrimonio heredado. La mera protección ya no sirve; es necesario avanzar un paso más y desarrollar una
Fig. I: Plaza de España "El Salón". Foto: Isabel Dugo 
nueva propuesta en términos positivos para conseguir una auténtica revitalización del centro de Écija. El futuro de la Ciudad histórica pasa, ineludiblemente, por la renovación de sus funciones urbanas como única garantía para que sigan siendo espacios vivos. Ello hace que no se trate únicamente de llevar a cabo actuaciones de carácter conservacionista -aspecto esencial en cualquier caso- sino que han de ponerse en relación con políticas de vivienda, políticas culturales, políticas de fomento económico o políticas sociales para conservar su diversidad social. Por demás, el valor histórico y cultural de Écija es uno de sus principales atractivos, tanto para sus habitantes, como para el sector económico. La protección y conservación del Casco no es, pues, un objetivo meramente estético o culturalista. Debe ser una política activa fundamental para hacer de Écija una ciudad marcada por la calidad de vida en un medio urbano de excepcional valor, y para fomentar el desarrollo de un modelo turístico de calidad.

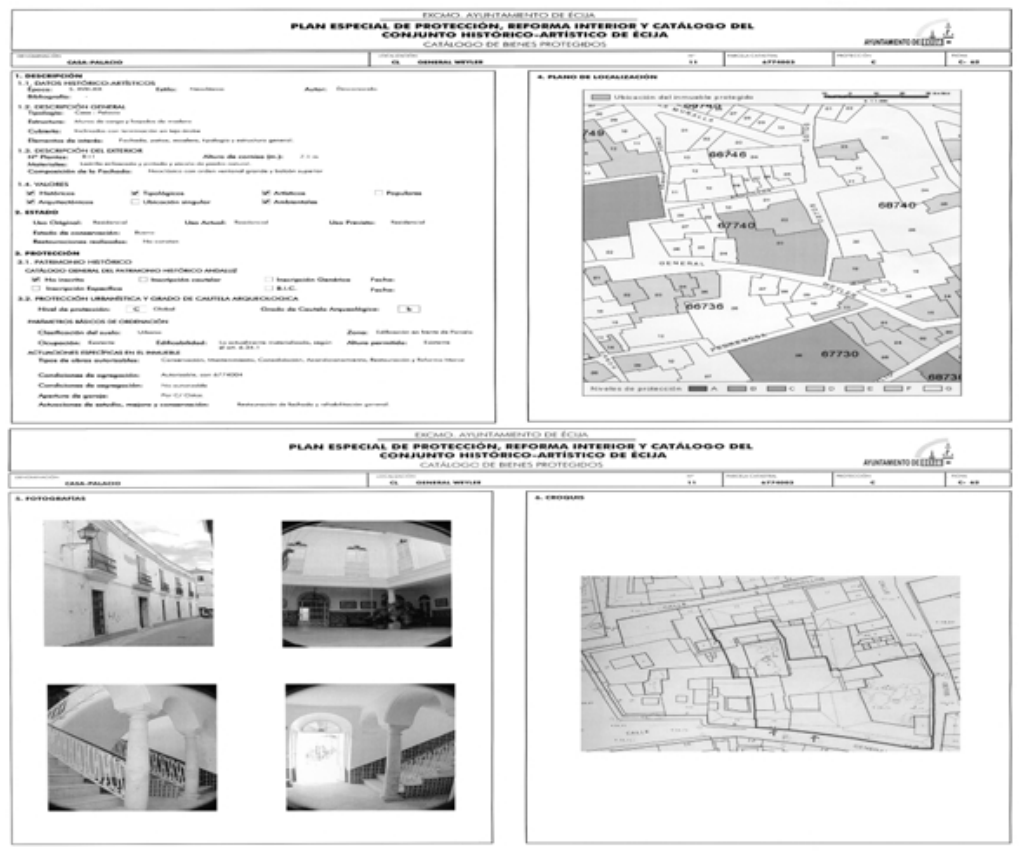

Fig. 2: Modelo de Ficha de Catálogo medidas para paliar la despoblación del centro; tanto por el fomento de la rehabilitación del patrimonio como por la creación de atractivos para la población joven, a partir de nuevas tipologías de vivienda e incentivos al alquiler; políticas de fomento económico, para conseguir que se sostengan sectores y actividades que dotan de funciones al espacio urbano; políticas sociales, que permitan conservar la diversidad social; o minoración de las agresiones medioambientales, potenciando el transporte público y posibilitando una mayor movilidad. La conservación de la memoria de los lugares históricos no es el archivo de lo existente, sino la invención del presente, $y$ en este sentido si la actividad tradicional del centro urbano es el comercio, los servicios personales, actividades de dirección y sobre todo, la residencial, la conservación de la función tradicional debe hacerse con los estándares que demanda la sociedad que es hoy destinataria de los mismos, con las limitaciones y atractivos de la conservación del patrimonio edificado.

Por último, y asociada directamente al carácter de Écija como ciudad histórica, ha de concederse especial importancia a la función cultural de la Ciudad. La puesta en valor del patrimonio histórico y los recursos culturales de nuestra Ciudad, ofrece una oportunidad para potenciarla a todos los niveles: comarcal, provincial, andaluz, nacional e internacional.

\section{EL CATÁLOGO DEL PLAN ESPECIAL DE PROTECCIÓN}

El ámbito del Plan Especial de Protección, Reforma Interior y Catálogo del Conjunto Histórico Artístico de la Ciudad de Écija (PEPRICCHA) engloba 328 I parcelas, espacios significativos, jardines y elementos construidos aislados. Este número incluye los 824 inmuebles construidos en los últimos años y 69 solares, lo que hace un total de 2388 edificaciones que podemos llamar tradicionales. También protege el nomenclator antiguo de las calles.

Afortunadamente los valores del patrimonio son hoy reconocidos por la sociedad en general; pueden considerarse superadas etapas en las que se les puso en alto riesgo de destrucción y de sometimiento a intereses particulares. No obstante es necesario ensanchar el concepto de ciudad histórica, atribuyéndole también aprecio cultural a otros espacios, edificios y usos menos antiguos que reflejen otros valores culturales.

La política de protección y conservación del patrimonio ha de ser, sobre todo, una política activa. El futuro de la ciudad histórica pasa, ineludiblemente, por el mantenimiento o la renovación de sus funciones urbanas (residenciales, comerciales...) como única garantía para seguir siendo espacios vivos. Ello hace que no se trate únicamente de llevar a cabo actuaciones de carácter cautelar sino que han de ponerse en relación con políticas de vivienda, con
Este ámbito viene delimitado según un plano existente de la Ciudad en la Iglesia de Santa María del año | 843 , por ser el de mayor antigüedad y precisión encontrado, tras lo cual se ha efectuado un reconocimiento in situ de las características de su trama urbana y de la antigüedad e interés de su edificación. Este reconocimiento, unido a un análisis detenido de los planos parcelarios, permite establecer con una gran exactitud el límite real de la trama histórica.

Hay que hacer notar que en el Conjunto Histórico Artístico de Écija existe un gran número de edificios que son merecedores de conservar ya que, aunque son elementos que no destacan de manera singular, forman la esencia de la trama histórica y el ambiente urbano característico de esta Ciudad. Sus muros, patios interiores y fachadas están siendo barridos por las construcciones modernas de mayor confort pero 
resultantes de una manera de vivir importada y sin identidad cultural propia. En concreto, se catalogan 1008 edificaciones (un 42,2\% del total) en todas sus categorías, 27 espacios urbanos, 20 elementos construidos aislados y los jardines de interés, además del nomenclátor de calles antiguo.

El proceso de los bienes a catalogar se fundamenta en los siguientes modos de alcanzar el suficiente grado de conocimiento al respecto como para poder tomar una decisión:

- La documentación escrita previa, tanto la bibliográfica como la procedente de documentos de planeamiento previo.

- La visita, y consiguiente estudio, de todos y cada uno de los inmuebles situados en el ámbito del Plan Especial.

- El consenso y la consulta en todo momento con los técnicos de la Junta de Andalucía.

Tras la selección previa, sometida a reconsideración permanentemente en el proceso, la fase de clasificación es la que conceptualmente ocupa el segundo lugar. A partir de la generalización de las características más comunes se agruparon los diferentes bienes a proteger. Tal clasificación, como ya previamente se podía prever por analogía con lo que sucede en otros Catálogos, no es suficiente para determinar de un modo adecuado la protección de cada bien. Por ello se ha establecido una segunda clasificación que determina el grado de protección genérica de cada inmueble, sin perjuicio de imponer, en los casos en que es preciso, determinaciones concretas recogidas en la ficha individual.

Por su extensión, y por las dificultades de acceso a muchos edificios, tales trabajos han exigido que la fase de información urbanística se dilatase hasta el final de la redacción, centrándose en un preciso y precioso trabajo de campo cuya finalidad era la de recabar in situ el mayor número de datos de entre los previamente decididos que debía contener cada ficha individualizada.

Los elementos que destacan sobre los demás son merecedores en la legislación actual de una protección identificada. Son los Bienes de Interés Cultural, en sus distintas categorías de Monumentos, Jardines Históricos, Conjuntos Históricos, Sitios Históricos, Zonas Arqueológicas, etc. Los Conjuntos Históricos, que se igualan legalmente con las distintas categorías, presentan una problemática tremendamente compleja en todos los órdenes, que en el caso de nuestra Ciudad se acrecienta, ya que su extensión abarca una gran superficie de la totalidad del suelo urbano.

Existe, por tanto, en la Ciudad de Écija, un abanico muy amplio de valores que hay que proteger, desde el enclave geográfico de la Ciudad y sus vistas, pasando por la calidad ambiental de los barrios, y la de la arquitectura e historia de sus monumentos y edificios singulares. Por esto, se han incluido en el presente Catálogo no sólo inmuebles, sino también los espacios urbanos y naturales, además de elementos singulares, que poseen un valor propio en la imagen histórica de la Ciudad.

En cuanto a los inmuebles, un primer criterio ha sido la singularidad del elemento. En este caso, todas las iglesias, conventos, palacios, etc. que, independientemente de su calidad y número de alteraciones que han sufrido a lo largo de su historia, son todos merecedores de protección, aun a pesar de quedar en algunos casos sólo partes de la arquitectura de la obra: fachadas, portadas, torres, etc.

Un segundo criterio ha sido su ubicación en la trama urbana, independientemente de su valor singular. Es éste el caso de los edificios residenciales de relativa relevancia si los consideramos como piezas aisladas, pero que en el conjunto de su calle o de su barrio o encontrarse en entornos de Bienes de Interés Cultural, son edificios que "hacen ciudad"; es decir, que por su uniformidad en la tipología de fachada, patios, etc. están contribuyendo a la creación de un ambiente urbano determinado.

Por tanto, con independencia de la protección de que gozan, o que pueden llegar a tener, algunos inmuebles por su inscripción en el Catálogo General del Patrimonio Histórico Andaluz y de la protección general del conjunto de las determinaciones del Plan Especial, los inmuebles incluidos en el Catálogo se dotan de protección urbanística concreta e individualizada por sus valores objetivos y singulares, por encontrarse en alguno o algunos de los siguientes grupos:

- Edificios singulares, fundamentales para la identificación e imagen de la Ciudad, por su calidad arquitectónica, su significación histórica, su uso especial, en general público, su antigüedad, escasez o rareza, o su representatividad de un período significativo.

- Edificios de interés arquitectónico, no singulares, cuya calidad compositiva o tipológica o la inclusión de algún elemento arquitectónico original contrastan dentro de la morfología urbana, constituyéndose en los ejemplos más depurados de la tipología tradicional de la Ciudad.

- Edificios de interés ambiental, cuyo valor reside en su fachada, como plano que conforma los espacios públicos, por componerla repitiendo las características invariantes de la Ciudad o por su singularidad como ejemplo de la arquitectura popular.

- Hitos, elementos urbanos, cuyo valor radica en su significado o en la singularidad de su forma o ubicación: templetes, oratorios, portadas de antiguos palacios, etc.

- Espacios urbanos significativos

- Jardines de interés, tanto públicos como privados

- Restos de estructuras arquitectónicas pretéritas o territorios sobre los que emergen y bajo cuya superficie se presume, por noticias bibliográficas, la existencia de restos muebles o inmuebles susceptibles de ser estudiados con métodos arqueológicos.

Como antecedentes de este trabajo se encuentran:

I. Catálogo del Plan General de Ordenación Urbana, aún en vigor, del que ya no existen algunos ele- 
mentos. Sólo incluye, además de los setenta y tres edificios contenidos en el Catálogo Arqueológico y Artístico de la Provincia de Sevilla, otros ochenta y cuatro edificios y elementos de protección ambiental de muy diverso carácter. En todo caso, la creación de la Comisión Local de Defensa del Patrimonio Artístico, que debe aprobar todas las intervenciones en las edificaciones, garantizaba la tutela de la Administración, tanto local como provincial, tanto en las obras de reforma como en las de nueva planta.

\section{Catálogo del Plan Especial de Protección del Con-} junto Histórico, que se aprobó provisionalmente.

3. Catálogo del Estudio de Definición del Conjunto Histórico de Écija, elaborado por la Dirección General de Bienes Culturales, de la Consejería de Cultura y Medio Ambiente de la Junta de Andalucía.

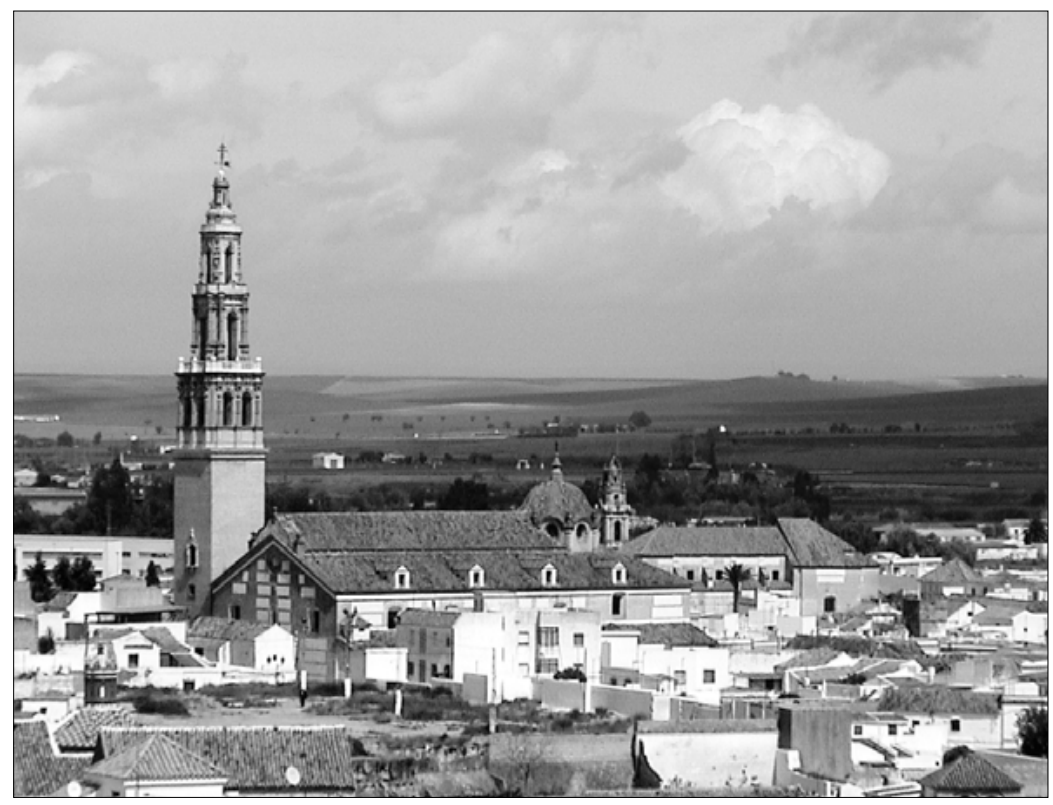

Fig. 3 : Nivel de protección monumental. Parroquia de San Gil. Foto: Isabel Dugo

Fig. 4: Nivel de protección integral. Arca Real del Agua.

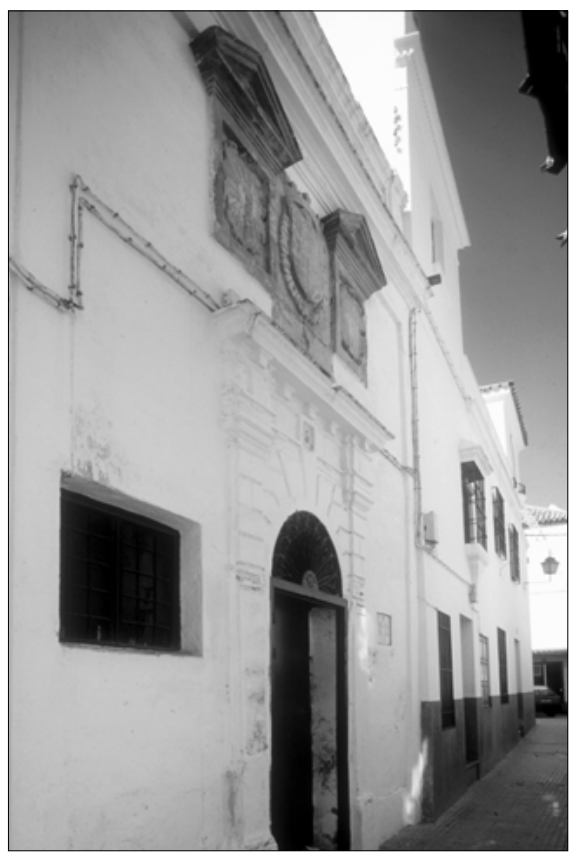

\section{Clasificación de los inmuebles protegidos}

Cada inmueble, según su naturaleza y condiciones, puede ser objeto de uno o varios grados de protección de entre los siguientes:

\section{Protección monumental}

Son los edificios fundamentales para la identificación e imagen de la Ciudad, por su calidad arquitectónica, su significación histórica, su uso especial, en general público, su ubicación aislada y focal, su antigüedad, escasez o rareza, o su representatividad de un período significativo. Incluye aquellos inmuebles que se encuentran en los siguientes grupos:

- Bienes de Interés Cultural Declarados

- Bienes de Interés Cultural Incoados

- Bienes de Interés Propuestos BIC

Todo edificio que durante la aprobación o vigencia de este Plan Especial sea Declarado o Incoado bien de Interés Cultural o se inscriba en el Catálogo General del Patrimonio Histórico Andaluz, tendrá automáticamente este Nivel de Protección. Los 22 edificios con protección monumental se señalan con la letra $A$.

\section{Protección integral}

Incluye aquellos inmuebles y elementos de excepcionales valores objetivos de carácter arquitectónico, histórico, artístico o típico que, con independencia de su estado de conservación deben mantenerse en su total integridad, con especial respeto científico de sus características singulares y de los elementos o partes concretas que lo componen. Se procurará la recuperación funcional y monumental por todos los medios de la técnica. Los 8 edificios comprendidos en esta categoría son identificados con la letra B.

\section{Protección global}

Incluye aquellos inmuebles y elementos de especial valor artístico, arquitectónico, pintoresco o típico que por sus características objetivas y por conformar el ambiente urbano en que se hallan, deben ser conservados con tratamientos específicos para mantener sus condiciones volumétricas, estructurales y tipológicas; $\sin$ perjuicio de obras interiores o exteriores de adaptación compatibles con el uso pertinente a su estructura y función urbana. Los 64 edificios comprendidos en esta categoría son identificados con la letra C.

\section{Protección tipológica}

La Protección Tipológica incluye aquellos inmuebles y elementos de especial valor arquitectónico, típico, pintoresco o ambiental que, si bien no alcanzan el valor singular que contienen los clasificados de Protección Monumental, Integral o Global, por sus características arquitectónicas originales o su significación en la historia de la Ciudad deben ser protegidos. Los 21 I edificios comprendidos en esta categoría son identificados con la letra D. 


\section{Protección parcial}

La Protección Parcial incluye aquellos inmuebles y elementos de especial valor arquitectónico, típico, pintoresco o ambiental, que si bien no alcanzan el valor singular que contienen los clasificados en los niveles de protección anteriores, por sus características arquitectónicas originales o su significación en la historia de la Ciudad deben ser protegidos. Los 258 edificios comprendidos en esta categoría son identificados con la letra $\mathrm{E}$.

\section{Protección ambiental}

La Protección Ambiental incluye aquellos inmuebles tradicionales que contribuyen a la configuración del ambiente general de la Ciudad histórica de Écija y del carácter del espacio urbano en que se encuentren situados. Por las características de su fachada, supone el mantenimiento integral de la misma, tanto de su estructura portante como de los elementos definitorios de composición, cerramiento, protección y revestimiento, así como del mismo tipo de cubierta, con las especificaciones que se establecen pormenorizadamente en las fichas del Catálogo. Los 407 edificios comprendidos en esta categoría son identificados con la letra F.

\section{Protección de la composición}

La Protección de la Composición incluye aquellos edificios cuyo valor reside en la fachada, como plano que conforma los espacios públicos, por componerla repitiendo las invariantes características de la Ciudad o por su singularidad como ejemplo de arquitectura popular. Por las características de su fachada, supone un régimen de permanencia que obliga al mantenimiento del sentido compositivo exterior de un inmueble irrecuperable y a la reposición de los elementos originales conservables, con las especificaciones que se establecen pormenorizadamente en las fichas del Catálogo. Los 38 edificios comprendidos en esta categoría son identificados con la letra $\mathrm{G}$.

\section{ACTUACIONES SINGULARES EN CURSO}

El gobierno del Excmo. Ayuntamiento de Écija en un intento de dar solución a la desactivación que el Casco Histórico de esta ciudad viene manifestando -especialmente en la última década-, y a la consiguiente situación de un proceso de obsolescencia que su arquitectura padece, plantea lo que en términos locales se ha denominado PROYECTO DE CIUDAD, que fundamentalmente consiste en la revitalización urbanística de su centro neurálgico, habiendo sido iniciados los expedientes correspondientes a Plaza de España, Teatro Municipal, Palacio de Benamejí -como museo histórico-Plaza de Abastos y Palacio de Peñaflor.

\section{I.- Plaza de España "el Salón"}

La necesidad de acometer una política de revitalización del comercio tradicional unida a una estrategia para resolver los incontables problemas de tráfico en esta zona y la ausencia total de una reserva de tal índole, pasan necesariamente, por el planteamiento de ejecutar un aparcamiento subterráneo bajo la superficie de la Plaza de España-El Salón-; por constituir el único área de grandes dimensiones equidistante de los puntos neurálgicos que son necesarios potenciar y dado el caso de encontrarse últimamente en condiciones de necesitar una urgente remodelación de sus elementos constituyentes: pavimentación, mobiliario urbano, iluminación, jardinería, etc., los cuales habían sufrido en los últimos cuarenta años cambios conceptuales - llevados a cabo de forma arbitraria y sin planteamiento de diseño urbano- que habían adulterado la fisonomía del vacío que dicha plaza constituyó a lo largo de la Historia, en el sentido que Gianugo Polesello entiende; es decir la "Arquitectura del Espacio Público" como recinto definido por arquitecturas murales que lo delimitan, Polesello dice: "Las plazas representan la imagen más habitual de espacio público en cuanto concluido, hueco. Como si la ciudad construida fuese un volumen compacto que es surcado por calles o del cual se excava una cantidad de materia que corresponde a una plaza, o en todo caso, a una ausencia de edificación".

Analizadas las distintas épocas en las que "El salón" protagonizó el Foro o Ágora contemporáneo es indudable que las imágenes de antaño son más reconocibles como definitorias de este recinto que la última imagen que nos había sido dada, por mucho que argumentos románticos o faltos de rigor intenten convencer a la ciudadanía de lo contrario. En este sentido la proliferación de masa arbórea de elección y forma descontrolada, la implantación de "parterres" que sólo servían para papelero o cama de perros, el desafortunado intento de implantación de setos que los surcaban unido a la instalación de bordes alambrados de pésima factura y el deplorable estado de su fuente central no hacían otra cosa que desvirtuar el hueco que una arquitectura de innegable calor circundante estaba solicitando.

La experiencia nos demuestra que un problema bien planteado es un problema medio resuelto; y que por el contrario en el supuesto de no ser bien planteadas todas sus incógnitas el problema no tendrá solución. En el caso que nos ocupa; el de la revitalización de un tejido urbano tan complejo como el Casco Histórico de Écija una postura ostracista ante la realidad de la existencia del automóvil pasaría por una alternativa parcial y falta de pragmatismo. La consideración contemporánea; estribaría en abordar la ejecución de este proyecto como una oportunidad para restaurar la superficie de nuestra adulterada plaza en base al análisis de su conformación original y de su conceptual trazado de espacio unitario. La propuesta pretende pivotar sobre el espacio público con la estrategia de usarlo para aparcamientos bajo su cota peatonal, como instrumento catalítico de todo el entorno de carácter histórico hoy deprimido.

El aparcamiento en si no es pues un objeto final sino que se trata de un instrumento, haciéndose necesa- 
ria su instrumentalización a base de un laborioso proyecto de cirugía urbana. La reserva subterránea por un lado y el efecto disuasorio de circulación que provocará el parking por otro, actuarán como instrumentos capaces de poder establecer áreas de peatonalización que de otro modo - con el tráfico actual - serían implanteables y que constituyen el fundamento de algunas principales Actuaciones de este Plan Especial:

PO-0I Ordenación de Plaza de España y Ejecución de Aparcamientos Subterráneos

PO-02 Peatonalización de Calle del Conde

PO-18 Peatonalización de Plaza de Santa María

PO-19 Peatonalización de c/ Compañía, Morería, Mas y Prat, $M^{a}$ guerrero y $S$. Francisco

PO-20 Peatonalización de c/ Cánovas del Castillo, E. Castelar, Castril, Galindo y Rueda

PO-2I Peatonalización de c/ Platería, Celestino Montero, Plaza de S. Juan y Arc. Aparicio

Igualmente y en un radio de 300 metros se hace necesario garantizar la optimización peatonal, no sólo a la trama comercial de pequeños establecimientos, oficinas tradicionales y estructuras de servicio, sino a toda la arquitectura previa que constituye con su presencia y monumentalidad de carácter de esta ciudad y que en este Plan Especial se revitaliza en gran medida y explicitadas igualmente en las siguientes actuaciones:

AA-5 Actuación Aislada. Adecuación Patio Iglesia San Juan para Auditorio al Aire Libre

AA-6 Obtención Convento de las Teresas y Rehabilitación para Equipamiento Público.

AA-7 Obtención y Rehabilitación Mirador Marqueses Peñaflor en Plaza España. Servicios

\footnotetext{
Fig. 5: Teatro Municipal.

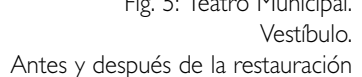

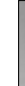
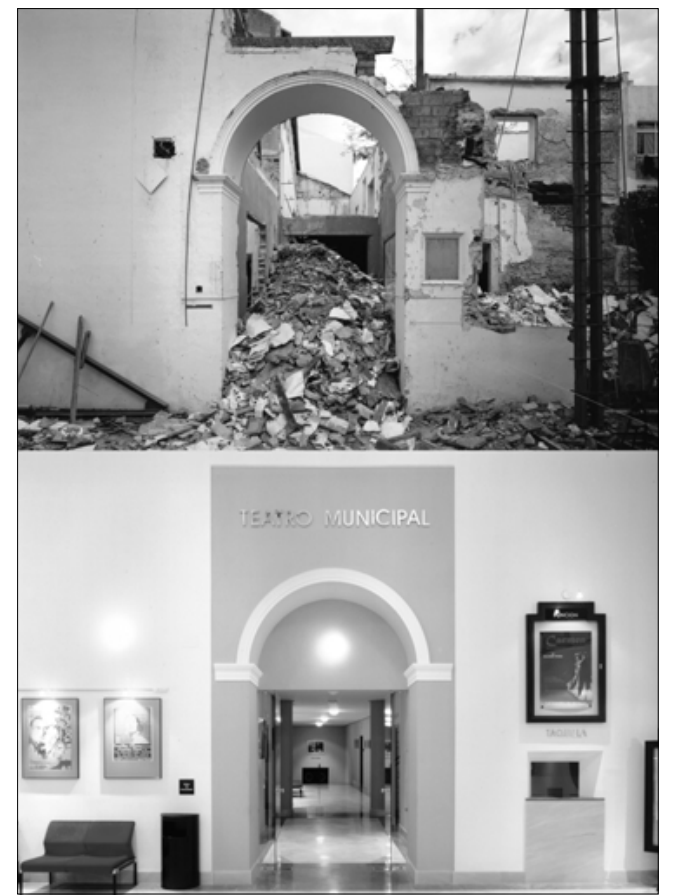

AA-8 Obtención y Rehabilitación Mirador Casa Benamejí en Plaza España. Servicios

AA-9 Obtención y Rehabilitación Casa Monumental en c/ Tello. Equipamiento Público

UE-2 Ordenación y Urbanización de la Plaza de Armas. Parque Arqueológico

PO-3 Rehabilitación del Palacio de Benamejí para Museo Histórico

PO-4 Rehabilitación del Palacio de Peñaflor para Uso Hotelero

PO-5 Rehabilitación de las Casas Anexas Palacio Peñaflor

PO-6 Rehabilitación de las Casas Anexas al Teatro Municipal para Escuela de Danza

PO-7 Rehabilitación de las Carnicería Reales para Mercado de Artesanía Local

PO-8 Rehabilitación del Arca Real del Agua. Museo de antigua instalación hidráulica

PO-9 Rehabilitación del Mercado de Abastos

PO-10 Rehabilitación Casa en Plaza Sta. María par Biblioteca y Archivo Histórico

PO-12 Rehabilitación Edificio c/ Evaristo Espinosa para Equipamiento Municipal

PO-22 Rehabilitación de la Casa Consistorial

PO-23 Arreglo de Fachada en Plaza de España. Adecuación al entorno

Como resumen de ambas relaciones se desprende una intención de peatonalización unida a una revitalización de edificios -la gran mayoría de propiedad municipal- para nuevos usos, tales como Mercado, Teatro, Escuela de Teatro, Auditorio, Biblioteca, Museo, Hotel, Equipamiento, etc., que unidas al conglomerado de viviendas tradicionales existentes en dicha área no son otra concepción que la de aquel memorable CIAM que se refería a la extensión de la vivienda a la ciudad complementándola con cuatro modalidades básicas: HABITAR, CIRCULAR, TRABAJAR Y DISTRAERSE.

José Luis Sert -presidente de los CIAM-, a propósito del terrible efecto que empezaban a producir los barrios periféricos y los nuevos centros en los CASCOS HISTORICOS escribía en The Heart of the City: "Este proceso de descentralización y especulación continua y descontrolada es una amenaza real para nuestras ciudades y para la estabilidad de los valores cívicos y favorece únicamente los intereses de unos pocos ente los intereses generales. Para acabar con este poseso de descentralización tenemos que invertir la corriente, es decir, tenemos que establecer lo que podríamos Ilamar un PROCESO DE RECENTRALIZACIÓN".

El reto en los Conjuntos Históricos estriba en obtener el equilibrio al que se refiere el concepto de CIUDAD SOSTENIBLE; no se trata tanto de conservar sino de renovar y obtener de una trama antigua una trama nueva capaz de producir lo que consume, de reponer lo que se destruye y de limpiar lo que ensucia. 


\section{Teatro Municipal. (Antiguo Teatro Sanjuan)}

Los antecedentes de la conocida "Casa de Comedias" de Écija se remontan al Cabildo celebrado en esta ciudad el 20 de Noviembre de 1617. Los diputados de Comedias nombrados al efecto, comprar unas casas propiedad de Dña. Inés de Henestrosa realizando las obras de forma acelerada, terminándose las mismas en 1621. A finales del Siglo XVII el Corral de Comedias se encontraba cerrado debido al periodo de crisis que atravesó la ciudad. No obstante a inicios de Siglo XVIII la Casa de Comedias se encontraba de nuevo en perfectas condiciones para acoger a comediantes. Durante todo el Siglo XIX fueron numerosas la representaciones teatrales en la referida Casa, que dejó de ser parte integrante del patrimonio municipal. A finales de Siglo XIX pasó a ser propiedad de D. Baldomero Custodio Fernández, de quien lo heredó su hijo D. Angel Custodio Fernández-Pintado. En 1927 fue adquirida por el industrial D. José Sanjuan Ariz, dejando de llamarse Teatro Custodio para convertirse en TEATRO SANJUAN, nombre que ha conservado hasta la última intervención reciente. En 1937 el edificio fue destruido por un incendio y siendo reedificado por su propietario para ser inaugurado nuevamente en 1940 inicialmente bajo la dirección de la Empresa Cabrera y después por la Sociedad Sanjuan hasta su cierre comercial en 1984. En Pleno Extraordinario celebrado por la Corporación Municipal de 20 de Agosto de 1990 se adquirió de nuevo por el Excmo. Ayuntamiento Écija.

El proyecto de remodelación del nuevo TEATRO MUNICIPAL fue redactado por los arquitectos Fernando Martín Sanjuan, Javier Madero Garfias y José Oliva Ladera en 1997 aprobado por Comisión Provincial de Patrimonio Histórico de fecha 4 de marzo de 1997 sobre la base de la recuperación de un edificio de carácter Ambiental con interesantes trazas Art-Deco é Historicistas. El expediente se lleva a cabo con la financiación del Excmo. Ayuntamiento de Écija y la Excma. Diputación Provincial de Sevilla por la empresa Constructora García Carrillo sobre un presupuesto aproximado de 340 millones de pesetas incluyendo instalaciones especiales, mobiliario y funcionando.

La superficie de las actuaciones es de $2.162 \mathrm{~m}^{2}$ desarrollando un programa con un aforo de 610 butacas que contempla el Salón de Actos (nivel bajo, gradas), Espacio Escénico con foso y peine completamente equipado, Gran Vestíbulo, Cafetería, Camerinos y Áreas de administración (actual Delegación de Cultura) y quedando pendiente la fase correspondiente a Escuela de Teatro y Danza (carga y descarga, aulas de danza y declamación, vestuarios, etc.) en solar anexo al espacio escénico propiedad del Excmo. Ayuntamiento y con acceso desde la antigua "barrera" de la calle Comedias con una superficie de actuación estimada de $392 \mathrm{~m}^{2}$ y un presupuesto de 49 mi\|lones que completarían el total de la intervención. El edificio fue reinaugurado en Enero de 1999 con la obra Carmen de Salvador Távora.

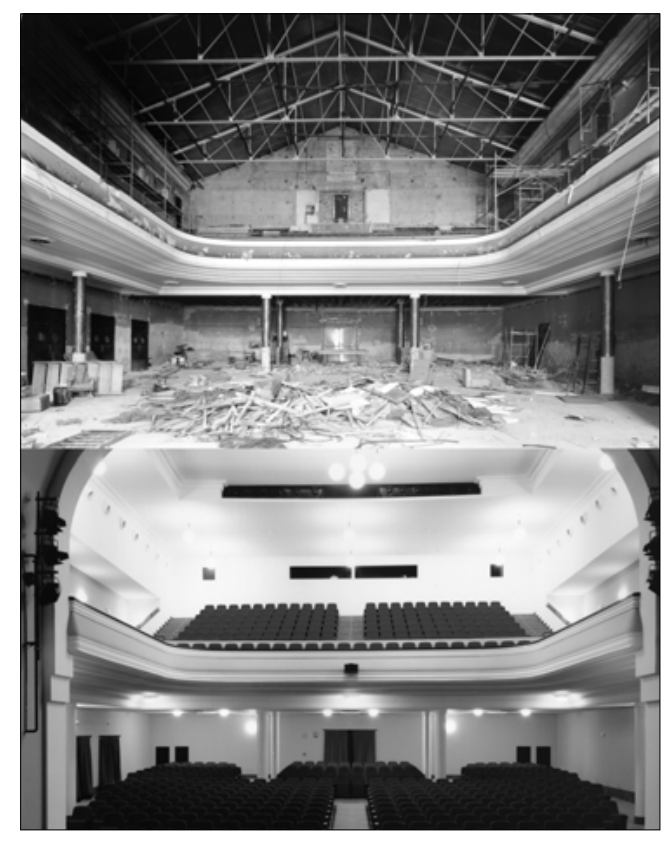

Fig. 6: Teatro Municipal.

Sala de butacas.

Antes y después de la restauración
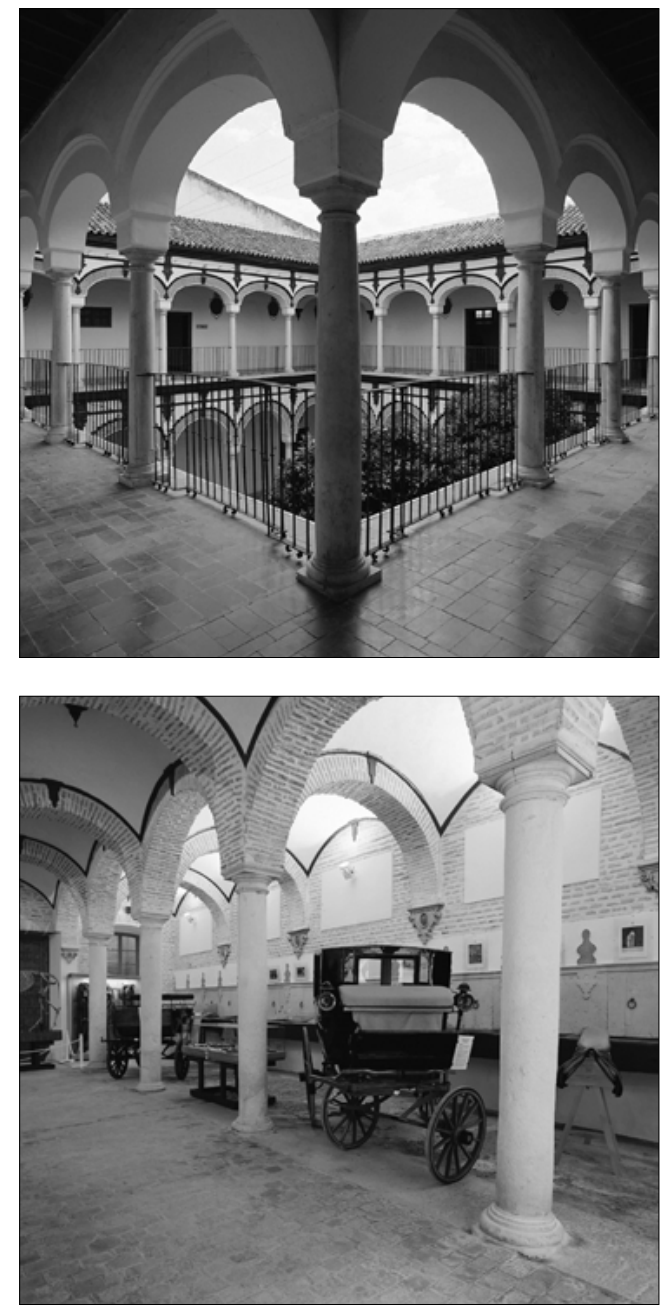

Fig. 7: Palacio de Benamejí. Patio.

Fig. 8: Palacio de Benamejí. Caballerizas.

\section{Palacio de Benamejí. Museo Histórico Municipal}

Constituye una de la piezas fundamentales de la arquitectura del Barroco Ecijano junto al Palacio de Peñaflor, dando ambos el tono cortesano al caserío de Ecija. Fue construido en el primer cuarto del si- 


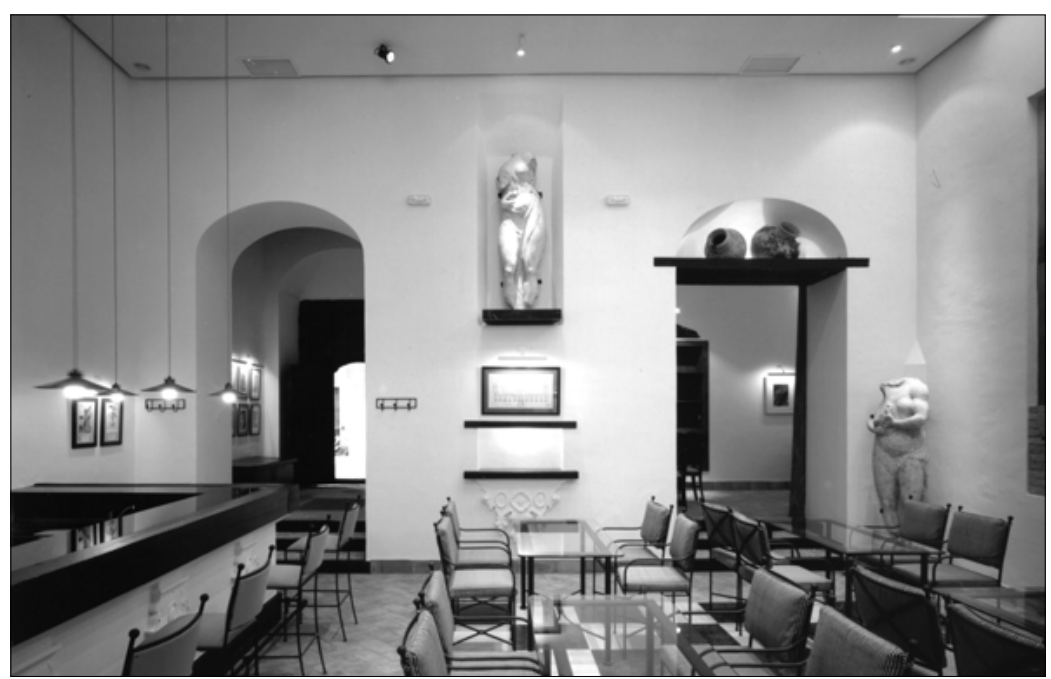

Fig. 9: Palacio de Benamejí: Restaurante

glo XVIII por los Señores Bernuy, marqueses de Benamejí, pasando luego a propiedad de los condes de Valverde, para finalmente pasar a propiedad de Excmo. Ayuntamiento de Ecija. Hasta fechas recientes y desde el inicio del siglo XX fue sede de la Comandancia Militar de Caballería.

Pieza modélica de la arquitectura civil del barroco andaluz y quizás la mejor joya del siglo écijano. Su planta responde a la tipología del palacio écijano; portada central sobre lienzo de fachada flanqueada por dos torreones que penetra a un gran apeadero que da acceso a las amplísimas caballerizas abovedadas situadas a la derecha de la entrada. Al fondo frente a la portada -bajo un enorme arco de ladrillo limpio que sostiene un balcón ricamente decorado con ladrillo tallado-, se abre la escalera, magnifica construcción de triple arquería lobulada y dos tiros cubierta con media naranja. Por el centro de ella se pasa al patio principal que ocupa el fondo del edificio de dos danzas de arcos sobre columnas y fuente central, decorado con ricos pinjantes de ladrillo. Los corredores de paso de gran dimensión conectan las distintas dependencias. La monumental fachada principal es quizás menos écijana -en su organización general- que la de los marqueses de Peñaflor (asimetría compositiva, curvatura del callejero, balcón corrido y gran guardapolvo pintado).

En la planta baja no tiene ningún hueco, como si se tratara de un gran pedestal de ladrillo que la hace inaccesible, presentando en la planta alta una serie de balcones con elegantes guarniciones de piedra. El conjunto con la gran portada robusta con dobles columnas a cada lado separadas del paramento, conforman un balcón enmarcado en su vano por una guarnición de estipites de policroma combinación de materiales. En el remate un airoso copete con escudos y acróteras terminales, tiene indudables analogías de composición y distribución volumétrica con la fachada del Seminario de San Termo de Sevilla.

La fecha de construcción de la portada (piedra blanca y gris) debió ser algo posterior a la del núcleo principal del edificio como lo prueban la presencia de los estipites citados y la aparición de la rocalla en las aplicaciones de bronce de la puerta cuyos clavos ostenta como motivo decorativo una barca, emblema de los Bernuy.

El día 27 de junio de 1995 y después de 89 años de permanencia del ejército en le Palacio se pone fin a ésta con el acto de "Arriar Bandera". Cuando en 1995 se comentaba la próxima salida de la Comandancia Militar de Caballería, se redactó el documento "BENAMEJI, UN MUSEO PARA LA HISTORIA", por un grupo de ecijanistas formado entre otros $y$ fundamentalmente por Rafael Armenta, Antonio Pedrosa, Fernando Luna, Juan Fernández y Juan Pliego en el que se dictaban las directrices y se daba forma a nivel de organigrama a la idea de ubicación de los distintos espacios culturales para el nuevo uso de Museo; se presentó al nuevo equipo de Gobierno Municipal y su alcalde el Sr. Álvarez Ortega, siendo acogido favorablemente y efectuándose la entrega formal del avance en Septiembre de 1996.

Posteriormente en diciembre de 1996 el Ayuntamiento en Pleno acordó por unanimidad la creación del Museo Histórico Municipal de Écija en el Palacio de Benamejí. El Excmo. Ayuntamiento de Écija y la Comisión Promotora creada al efecto abren de nuevo las puertas del Palacio al pueblo écijano el 8 de marzo de 1997 para la presentación del proyecto del Nuevo Museo. Para esta fecha se habían realizado obras de adecentamiento de las áreas de planta baja fundamentalmente las referentes a la creación de un espacio para Exposiciones temporales, la Oficina de Turismo, el Salón de Actos, dos Salas de Arqueología, una Sala de Arte Ecuestre y los Aseos, así como recuperación de los espacios del patio y anexos de la casa de servidumbre (acceso por c/. Rueda) para almacén y tallerlaboratorio de restauración. Paralelamente, la Comisión Municipal de Gobierno del Excmo. Ayuntamiento de Écija de 25 de febrero de 1997 determinó la contratación de Consultoría y Asistencia para la redacción de Proyecto de Rehabilitación y Reforma del Palacio, así como para el asesoramiento de los Técnicos Municipales al arquitecto Fernando Martín Sanjuan con la determinación de redactar el documento con el soporte de la Oficina Técnica del Área de Urbanismo la asistencia de especificaciones sobre el cálculo de la estructura del Ingeniero de Caminos D. Luis Moral Ordóñez y de las Mediciones y Presupuesto de los Arquitectos Técnicos D. Francisco M. Martín Ojeda y D. lavier Muñoz Yribarren.

En el transcurso de 1997 se finalizaron dos expedientes; uno correspondiente al Proyecto Básico con avance de superficies y presupuesto para presentación ante la Comisión Provincial de Patrimonio de Sevilla -habiéndose realizado visita conjunta al inmueble y las obras comenzadas con la Delegada de la Consejería de Cultura de Sevilla Da. Pilar Gómez-Casero y el Arquitecto Responsable de Patrimonio Sr. Mena Anisi-y otro expediente parcial referente a área correspondiente a Recursos-Ociosos (Cafetería, Restaurante y Tienda) siendo promotor el Ayuntamiento de Écija en cooperación con Fondo Europeo de Desa- 
rrollo Regional a través de la Sociedad Sevilla Siglo XXI S.A. de la Diputación de Sevilla, habiendo sido finalizadas estas obras y complementadas con el anexo de rehabilitación de la cubiertas del torreón sur y la escalera de caracol de acceso con un presupuesto aproximado de 43 millones de pesetas en el que se incluyeron instalaciones especiales, cocina industrial y mobiliario. Posteriormente se realizó otro expediente referente a la restauración de ambos torreones para hacerlos visitables como panorámicos en cooperación con la Consejería de Turismo y Deporte, con un presupuesto aproximado de 26 millones de pesetas encontrándose las obras en ejecución y próximas a su finalización. Ambos expedientes de obra adjudicados a la Empresa Constructora García Carrillo bajo la dirección del Director del Departamento de Casco Histórico Fernando Martín Sanjuan y la colaboración del arquitecto Diego Martínez Mérida en el primero y Tomás Rojas Losada en el segundo.

El ultimo expediente -actualmente en fase de proyecto- y programado para el año 2002 consiste en la remodelación estructural e integral de las cubiertas del Palacio con una estimación económica de 106 millones de pesetas debiéndose ser considerado de urgencia y como inmediata su ejecución, la cual hará factible el desarrollo de la funciones de Planta Alta referente a Epoca Romana, Edad Media, Siglo XVIII Écijano, Epoca Contemporánea, Patio de Esculturas al aire libre, Residencia para Investigadores, Administración y Sala de Juntas entre otras.

Las directrices seguidas en la elaboración de la propuesta se basan fundamentalmente en el análisis del mantenimiento de la morfología y trazas originarias del inmueble, eliminando las edificaciones y adulteraciones de facturas posteriores a la originaria e identificando las características espaciales más idóneas para los nuevos usos proyectados permitiendo que sea el propio edificio el generador del resultado final, habiéndose tenido en cuenta las nuevas ordenanzas referentes al Decreto 72/92 sobre eliminación de barreras arquitectónicas así como las especifica de la NBE - CPI - 96 actuando con la máxima estrategia en la ubicación de elementos que hagan factible el cumplimiento de la normativa vigente. La superficie construida total arroja un sumatorio de $3.860 \mathrm{~m}^{2}$ con una estimación global de presupuesto de 450 millones de pesetas.

\section{Plaza de abastos}

El Ministerio de Fomento, dentro de sus programas de rehabilitación y recuperación de los Centros Históricos, contempla la rehabilitación de edificios de titularidad pública, contando para ello con un programa de financiación a cargo del I\% Cultural. La Rehabilitación de la Plaza Municipal de Abastos de Ecija, forma parte de este programa, encomendándose la redacción del Proyecto a Rita Lorite, arquitecto del Área de Proyectos y Obras de la Subdirección General de Arquitectura, Dirección General de la Vivienda, la Arquitectura y el Urbanismo, de este

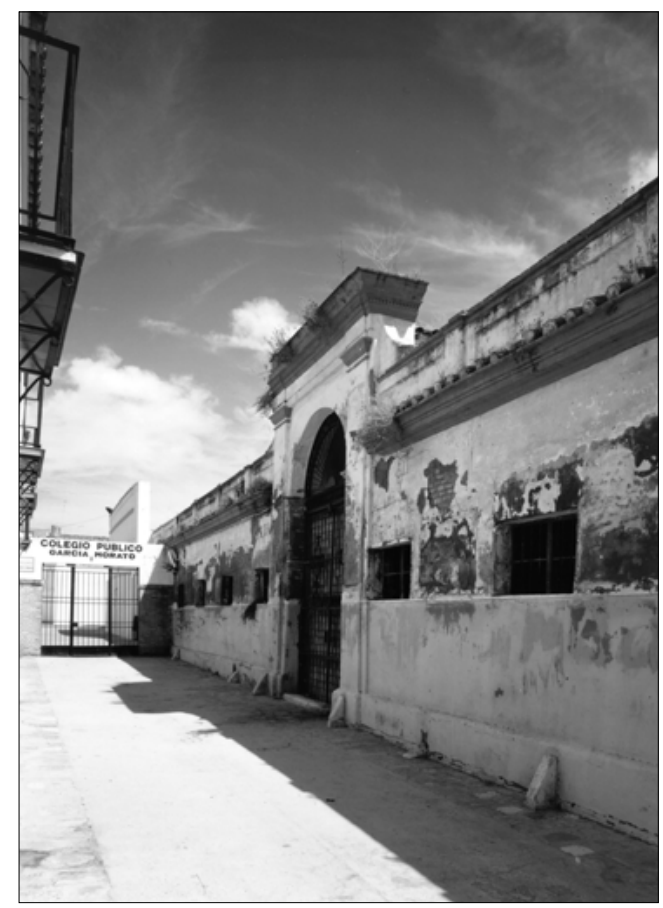

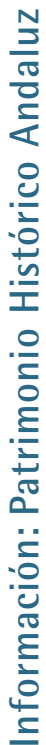

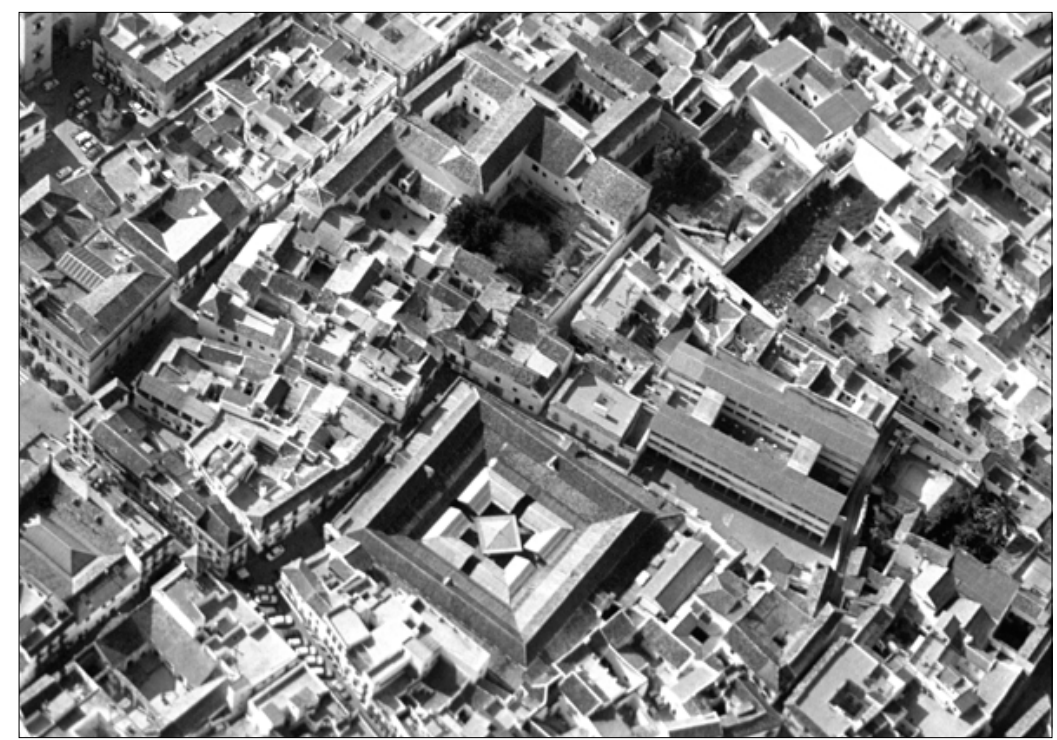

Ministerio. El Acuerdo de Financiación se determina entre el Ministerio de Fomento, la Junta de Andalucía, el Excmo. Ayuntamiento de Ecija y la Empresa Nacional MERCASA.

Fig. 10: Plaza de abastos

Fig. I : Plaza de abastos. Vista aérea Foto: Isabel Dugo
La actuación consiste en la remodelación de un mercado neoclásico construido en 1843 (sobre el desaparecido Colegio e Iglesia de San Fulgencio que perteneció a la extinguida Compañía de Jesús) por el Marques del Arenal presidiendo los objetivos de la Sociedad de Fomento constituida con la idea de solucionar los problemas de higiene y salubridad y con la finalidad de abolir el viejo mercado ambulante -que se remontaba a la época medieval-, y que se celebraba al aire libre en la Plaza Mayor. El edificio tiene forma de claustro cuadrangular con nave periférica a dos aguas con cuatro penetraciones de puertas apilastradas con cancelas a las cuatros orientaciones, con plaza central en la que se ubica 


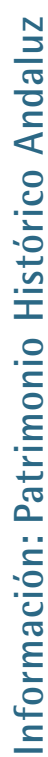

un Kiosco destinado a cafetería, jardinería, toldos y espacio de estancia. Se arbitran 27 puestos periféricos, 36 puestos centrales y 20 locales a patio que hacen un total de 83 puestos para comerciantes locales tradicionales, parte de los cuales en la actualidad han sido ubicados en un Mercado provisional organizado al efecto por el Excmo. Ayuntamiento de Ecija. En la actualidad se encuentra en ejecución avanzada de obra sobre la base de un presupuesto aproximado de 520 millones de pesetas que incluyen tanto las obras de rehabilitación integral como las de instalaciones especiales, cámaras, aire acondicionado etc., y en la línea de transformar el obsoleto edificio (últimamente cerrado al publico dado el caso de no cumplir condiciones mínimas de salubridad) en un moderno y actualizado Centro Comercial capaz de servir como una de las locomotoras que reactiven el Centro Histórico de Ecija. Afortunadamente coincidente con el centro geográfico, el cual necesita para su recuperación el impulso y la revitalización que el carácter de un edificio de tal categoría puede imprimir.

La obras fueron adjudicadas a la Empresa NECSO. Entrecanales y Cubiertas S.A. habiendo dado comienzo en Junio de 200 I y teniendo previsto su terminación para finales de 2002.

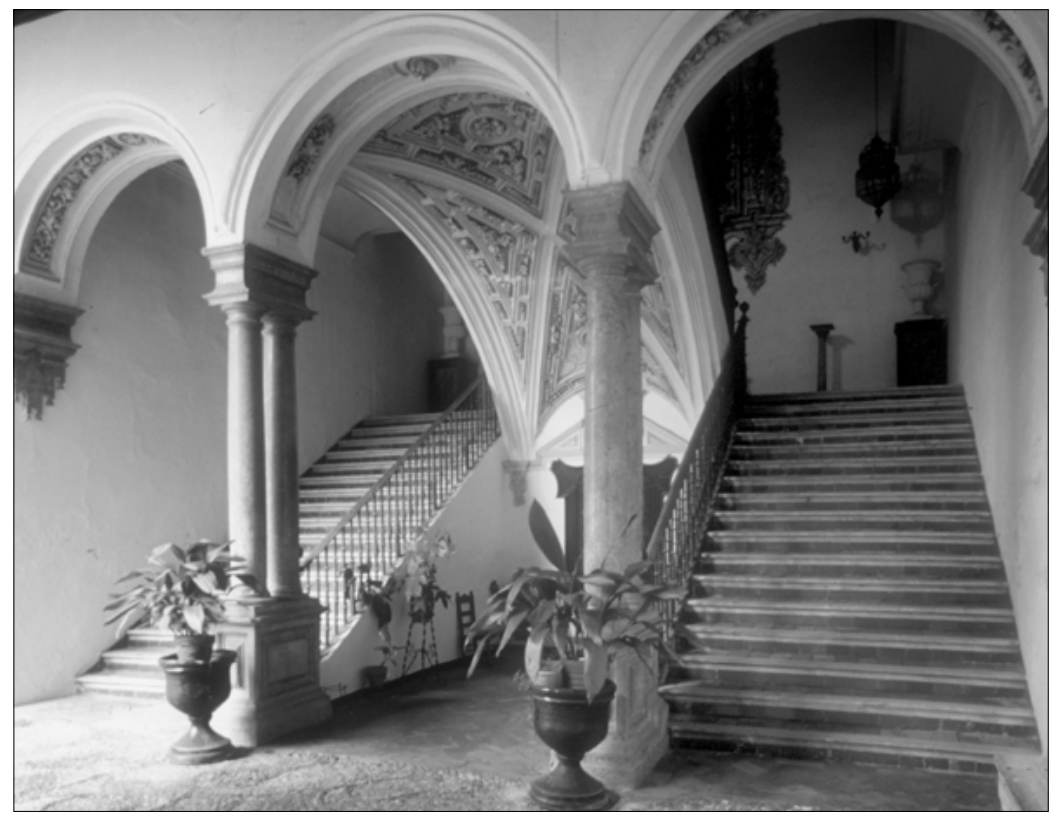

Fig. 12: Palacio de los Marqueses de Peñaflor.

\section{Palacio de los Marqueses de Peñaflor}

El Palacio de los Marqueses de Peñaflor está declarado Bien de Interés Cultural, y cuenta con el Nivel de Protección Monumental (A) en el PEPRICHA. Este Plan Especial prevé en el edificio un equipamiento hotelero. Se trata de acondicionar este edificio de interés arquitectónico. El Palacio y su entorno quedan englobados en un área alrededor de los trescientos metros de la Plaza de España, con una serie de recorridos peatonales, en la que se encuentra la zona más monumental de la ciudad.
Como premisas de partida para la redacción del Proyecto, están por un lado la mejor conservación del edificio, la adecuación del mismo desde el punto de vista funcional, y por otro la consideración de tratarse de una actuación en tan singular edificio, con el máximo nivel de catalogación, dadas sus características arquitectónicas, tipológicas, históricas y monumentales. Trata, por tanto, de la restauración del Palacio de los Marqueses de Peñaflor, de importancia no sólo a nivel local, sino nacional, como se refleja en su Declaración de Bien de Interés Cultural. Se pone en valor turístico este edificio patrimonial singular. Además, se embellece la totalidad del Conjunto Histórico y es foco de atención turística, al actuar sobre el palacio más característico y singular de la Ciudad. El Arquitecto Fernando J. González Beviá ha redactado los siguientes proyectos relacionados con el monumento: Rehabilitación de las Casas Anejas, Rehabilitación de la Casa de Campo, Restauración de la fachada principal y Rehabilitación del Palacio para uso hotelero. En la actualidad se está ejecutando la rehabilitación en las Casas Anejas y la Casa de Campo. Son las zonas menos nobles del conjunto edificatorio, aunque también forman parte del complejo hotelero.

El edificio barroco, Palacio, Zona Noble, es la que se encuentra en mejor estado de conservación, ya que tanto la Casa de Campo como las Casas Anejas tienen muchas áreas arruinadas, sin cubierta y con muros desplomados. La intervención en la Zona Noble se fundamentará en su Nivel de Protección, que implicará actuaciones técnicas para la consolidación estructural de sus muros, recuperación de sus forjados, revestimientos, reparación de cubiertas, carpinterías, reposición de pavimentos, reconstrucción de zonas en ruinas, eliminación de añadidos y particiones que rompen la estructura original del edificio, estudio del color, de los frescos de la fachada, realizar catas para encontrar paramentos pintados al fresco, tratamiento de elementos singulares, como columnas de piedra, mármoles y piedras de la fachada, cornucopias de ágata y zócalos del mismo material del patio principal, yeserías, tratamiento de la madera y canes de las salas principales...

Desde el punto de vista funcional, el programa de necesidades y la estructura organizativa interna del edificio nos ha conducido a establecer una serie de pautas en la definición del proyecto:

- Recuperación de los espacios a su estado original, eliminando aquellos elementos, como particiones, cerrado de huecos, etc., que desdibujan su traza barroca.

- Control, recepción, consigna, zonas comunes en la entrada, apeadero y alrededor del patio principal.

- Los grandes salones en todas las plantas se usan para zonas comunes ya que, por sus dimensiones y ubicación, y también para conservarlas en su estado original, parecen las idóneas.

- En la Zona Noble se ubican también las habitaciones más representativas del hotel y de mayores dimensiones. 
- Se aprovechan la Casa de Campo y las Casas Anejas para situar más habitaciones del hotel de naturaleza más doméstica.

- Se plantean en zonas estratégicas los servicios comunes y funcionales para el uso al que se destina.

Se ha articulado toda el área de intervención, creando unos recorridos y una permeabilidad que registre toda la planta.

Hay que repetir que nos encontramos ante un edificio declarado como Bien de Interés Cultural y que, de entrada, estaremos dispensados de cumplir algún requisito en aras de mantener los valores arquitectónicos del mismo. La idea que se tiene de hotel en este singular edificio es de un alojamiento con grandes habitaciones y suites, sobre todo en la Zona Noble, que no desdibuje la traza original del edificio subdividiéndolo demasiado. Cada habitación dispondrá de salón, alcoba y baño completo. Hay, por tanto, amplias habitaciones, algunas tipo dúplex, que son más reducidas en espacios más rurales como son la Casa de Campo y las Casas Anejas.

Se actúa sobre un área global de $6.870 \mathrm{~m}^{2}$ de los cuales actualmente se está interviniendo en aproximadamente $1.500 \mathrm{~m}^{2}$ correspondientes a Casa de Campo y Casas Anejas. El número de habitaciones del futuro hotel será de 50 unidades dobles de 5 estrellas con un presupuesto aproximado de 995 millones de pesetas, de los que la restauración de la fachada, sumada a la Casa de Campo y anejas, representan el 30\% del total de la actuación.

\section{INTERVENCIONES ARQUEOLÓGICAS}

\section{Plaza de España "el Salón”}

Los sondeos arqueológicos de valoración realizados en 1998, en la Plaza de España de Écija, van a poner de evidencia una vez más la excepcional riqueza patrimonial de este municipio. Muchas eran las hipótesis vertidas sobre este espacio, pero no será hasta este momento cuando se sienten las bases de estudio de una secuencia histórica llena de matices, que

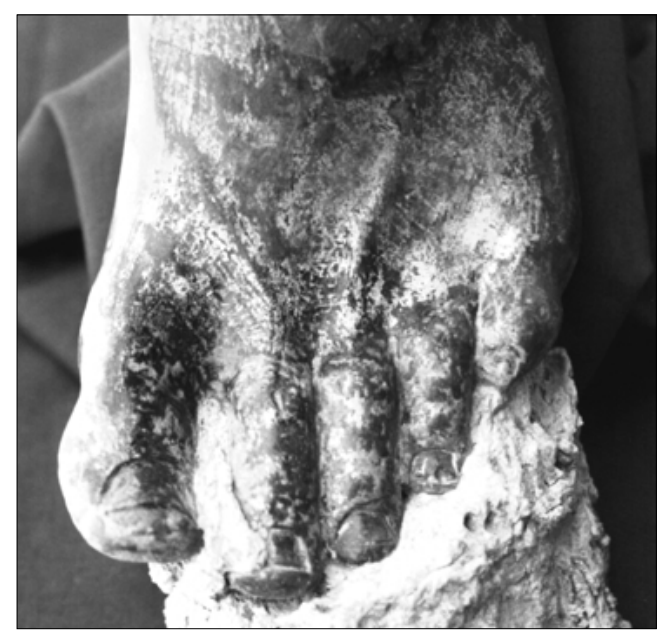

como pocas ha conservado para el investigador, evidencias de los drásticos cambios de uso de que fue objeto, merced a las necesidades de las diferentes culturas y momentos históricos 1.

En la base de la secuencia, a unos cuatro metros de profundidad, asistimos a unos estratos, donde los efectos de la dinámica fluvial están presentes de manera notable: depósitos de arena y gravilla, alternan con limos, cuyo contenido en adobes y fragmentos cerámicos nos evidencia el inicio de la presencia antrópica en el sector. Esto dará lugar a fuertes colmataciones, que cristalizan en el primer expediente constructivo detectado hasta la fecha, que ocupa y ordena este espacio por vez primera. Será lo que hemos identificado como el conjunto termal del foro astigitano, vinculado a las nuevas formas urbanas que adquirirá la ciudad con su nombramiento como colonia.

De esta fase, que datamos a partir de mediados del s. I d.C., y que estará en vigor hasta el siglo IV d.C., destaca ante todo la gran estructura hidráulica detectada, de más de 16,00 m de longitud, 6,00 m de anchura y I,36 m de profundidad y que se extiende sin solución de continuidad hacia el este. Construida en opus caementicium, iría revestida por el interior de opus signinum, y decorada -según la técnica y los derrumbes asociados-, por estucos en tonos rojos, blancos y amarillos; algunos restos de aristas evidencian la existencia de columnas estucadas que debieron pertenecer a este primer momento constructivo. En el paramento norte, inserto en el bocel de opus signinum, se detectó el desagüe de drenaje; se trata de una tubería de plomo de sección circular, apoyada en una plancha horizontal del mismo material, precedida de una leve depresión que serviría para decantar las impurezas del agua. Asociado a la misma, se detectó en toda la mitad oriental de la plaza, una superficie de tierra alberi-

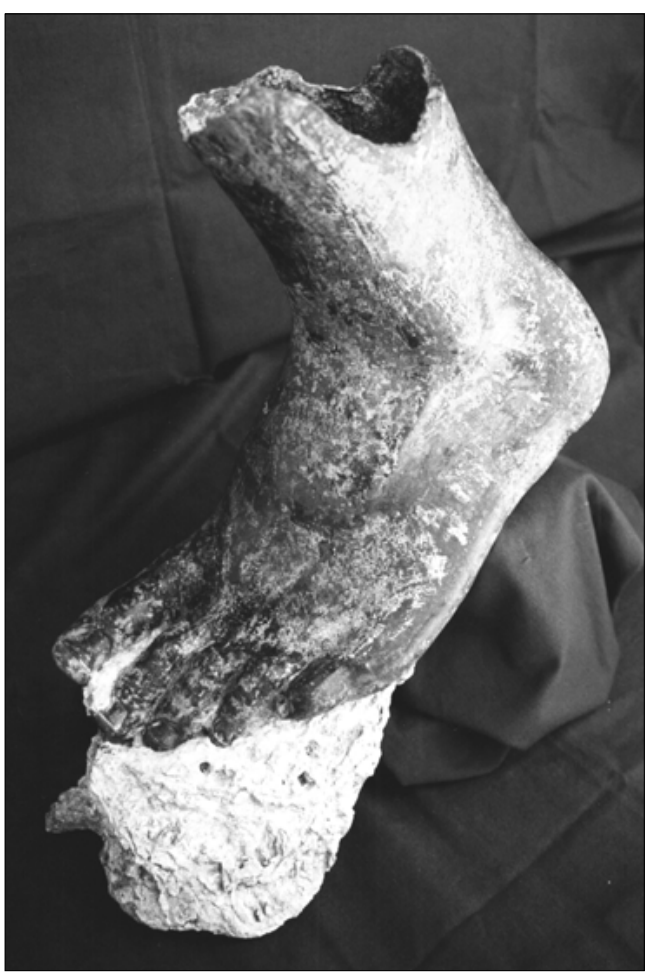

Figs. 13 y 14: Pie de bronce dorado, detectado en los derrumbes del s. IV d.C. de la natatio y detalle frontal. 


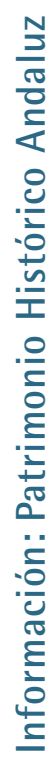
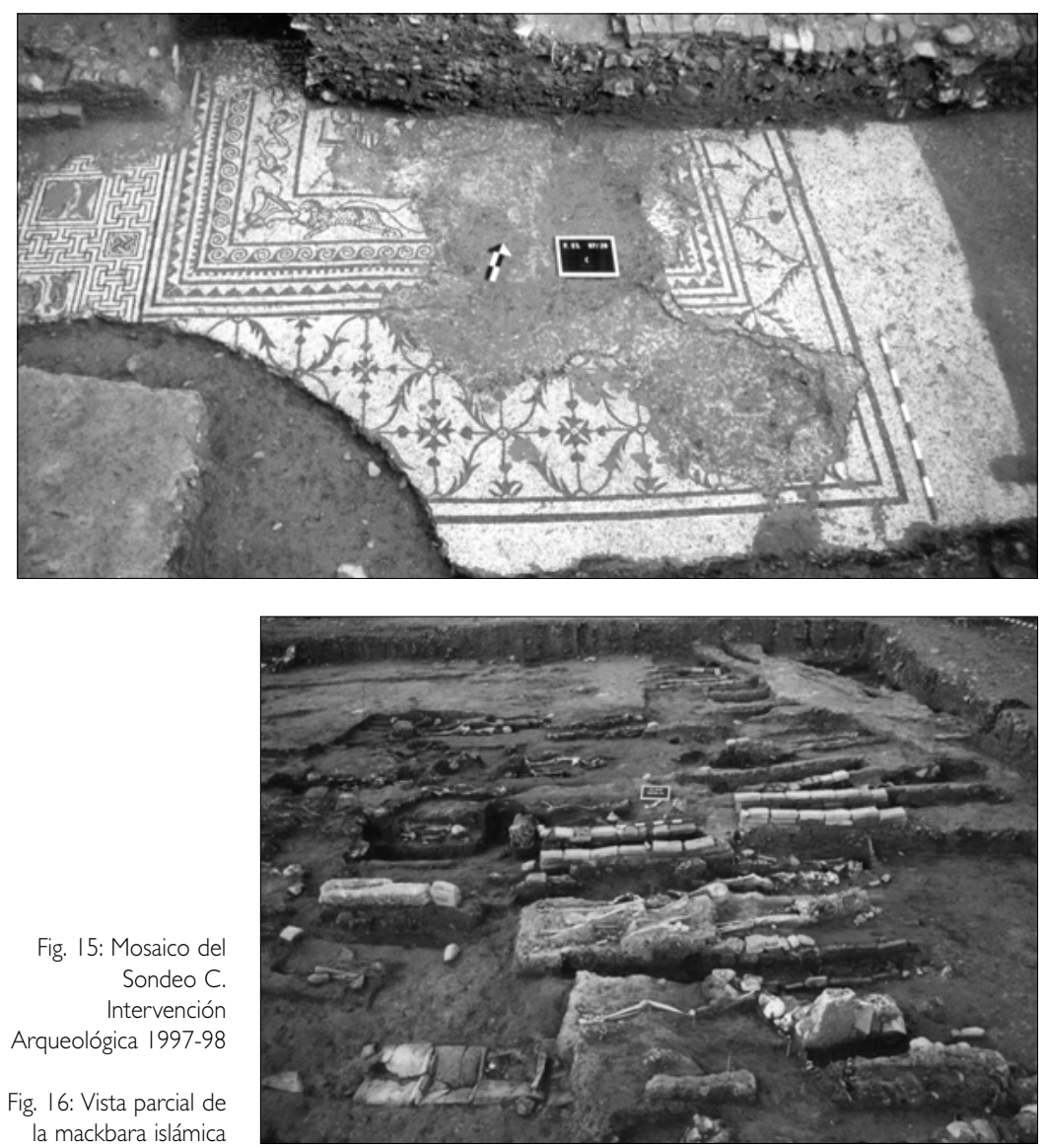

frisos decorados de mármol, capiteles corintios, cornisas de gran formato, etc., así como abundantes ortostatos en mármoles de importación: giallo antico, pavonazzetto, africano, portasanta, verde antico, pórfido rosso, serpentino, etc.; así como otros mármoles y piedras locales, de las cuales estamos procediendo a un exhaustivo estudio para poder objetivar las toneladas importadas de cada cantera.

Hacia la mitad occidental de la plaza, en torno al s. III d.C., parecen desarrollarse espacios de carácter doméstico, pavimentados con mosaicos, de los cuales hasta la fecha hemos podido exhumar un triunfo de Baco muy deteriorado, entre orlas florales, acompañadas por felinos, palomas, patos, y delfines; así como otro emblema con motivo de rostro cubierto que parece asimilarse a la iconografía del Invierno por los árboles desnudos que le acompañan.

Tras unos leves episodios naturales que colmatan de limos los derrumbes de la natatio, un nuevo expediente constructivo, va a ocupar el espacio que analizamos, a veces compartimentando las antiguas estancias; se trata de una serie de muros, de técnica poco cuidada y material de acarreo que datamos en un momento aún por definir entre el s. IV y $\vee$ d.C.

Y abriéndose paso entre los derrumbes y estructuras romanas, aparecen excavadas las primeras evidencias funerarias altomedievales, que con una potencia de I,24 m en la estratigrafía, y una extensión que sobrepasa los límites de la plaza actual, podemos calificar de la mayor mackbara documentada hasta la fecha en la península. La estratificación de las tumbas en ocho o nueve fases superpuestas, y la alta densidad de individuos, nos hacen confirmar que se trata del cementerio islámico de Istiyya, hipótesis apoyada por los estudios antropológicos que se vienen realizando, donde se ratifica un muestreo poblacional diverso respecto de grupos de edades y sexos ${ }^{2}$. La ubicación de esta mackbara dentro del perímetro de la muralla no es ajena a otros casos como la necrópolis sari'a qadima de Almería ${ }^{3}$ y las de San Nicolás o Santa Eulalia en Murcia ${ }^{4}$. El ritual es la inhumación individual en decúbito lateral derecho, sin ajuar ni epígrafes de identificación. La estructura funeraria más frecuente es la fosa simple, predominante en todas las fases del cementerio; en menor proporción, aunque también desde los primeros momentos, constatamos estructuras de adobe, normalmente dos muretes paralelos sin cierre en los extremos cortos; y por último, ya en las estratificaciones más tardías observamos algunas tumbas de ladrillo, siguiendo la morfometría de las anteriores. Sobre estos tipos básicos se observan muchas variaciones, como el distinto módulo de adobe, la aparición o no de cubierta, el uso combinado de materiales, la utilización de piezas de acarreo, etc. El estudio arqueológico está barajando en la actualidad unas cronologías que van desde el siglo IX al XII, y la analítica antropológica está llevando a cabo un estudio que pasa no solo por los diagnósticos de edad y sexo, morfología de la población, o paleopatologías diversas, sino que atañe a caracterizaciones sociales como la esperanza de vida, la talla media, aspectos anémicos, de salubridad, dieta, etc.

Andando el tiempo, el s. XIV será el siguiente que deje su impronta, socavando y removiendo con amplias fosas el área de cementerio islámico. Podemos vincular este período a una actividad sucedánea o parasitaria, de los cambios de uso que se están produciendo en el entorno en estos momentos, con la inserción de polos de atracción religiosa o civil como el Convento de San Francisco, la iglesia de Santa Bárbara, etc. Mas adelante tan solo tendremos los suce- 
sivos sellamientos efectuados por las repavimentaciones del nuevo espacio público: la plaza mayor de la Écija moderna y algunas canalizaciones del s. XVIII y otras de principios del s. $X X$, relacionadas con los abastecimientos de agua tanto de las fuentes como la relacionada con los servicios públicos subterráneos ubicados en el extremo noreste de la Plaza.

\section{Plaza de Armas del Alcázar}

En el estado actual de nuestros conocimientos, hemos de pensar que los primeros pobladores de lo que hoy constituye la ciudad de Écija debieron asentarse en el promontorio elevado sobre la llanura del Genil que constituía el cerro de la Plaza de Armas, denominado popularmente "el Picadero", en el siglo VIII a.C., en esa época en la que se produce la reactivación de diversos núcleos de población en toda la Andalucía Occidental, incentivados, suponemos, por la presencia de los colonizadores orientales, fundamentalmente de la franja sirio-palestina, que forman la base de lo que conocemos como colonización fenicia.

Así, los restos conocidos de este período orientalizante se encuentran ubicados en los alrededores de la Plaza de Armas, en la c/ Merced, 5, donde se excavaron dos fondos de cabañas de forma rectangular, separados por una calle pavimentada con guijarros, correspondientes a los siglos VII-VI a.C. a juzgar por los restos cerámicos hallados. Entre ellos se documenta el repertorio indígena del Bronce Final pero también las primeras importaciones de cerámica a torno de origen fenicio. Por ello, creemos que el núcleo original de la actual ciudad de Écija se ubica en esta zona del "Picadero", que como ya hemos señalado es la de cota más elevada dentro del casco histórico.

Para la época posterior turdetana, y a juzgar por los datos a nuestra disposición, el poblamiento primitivo parece mantenerse en el área originaria, como indican los hallazgos de las calles Alcázar, 38 y Merced, 35 y 37, extendiéndose hacia las laderas este y oeste del cerro del "Picadero" según se deduce de las excavaciones de las calles San Marcos, 9 y 9 a y 27. Mármoles, 6 y Mármoles esquina con Miguel de Cervantes, Garcilópez, 10, con materiales, en algunos casos, que llegan hasta época romana republicana. Es posible que la expansión hacia el este y sur estuviese condicionada por el Genil, aunque no podemos descartar una expansión también hacia el norte, a pesar de que los datos a nuestra disposición en la actualidad no lo indiquen.

La zona de la Plaza de Armas parece ser también el emplazamiento originario que correspondería a la ciudad que en Plinio encontramos con el nombre de Astigi Vetus (Plin. N.H.III.3. I2), es decir, la ciudad ya conocida por los romanos previa a la fundación de la Colonia Augusta Firma Astigi. Curiosamente, desde el punto de vista de la documentación escrita esta Astigi Vetus sólo se menciona en el anterior pasaje de Plinio, si exceptuamos una cita de Apiano, referida a las guerras lusitanas, en donde se menciona una Eiskadía que ha sido identificada con Astigi por algunos historiadores, aunque no creemos que dicha identificación sea fiable (Apian. Ib. 68). No parece, por tanto, que la ciudad anterior a la fundación colonial tuviese un peso importante como centro de poder en la zona. El hecho mismo de que no encontremos referencias a ella durante la época de la conquista romana ni durante las guerras civiles del siglo I a.C., que tienen uno de sus escenarios en esta zona, avala esta hipótesis.

Teniendo en cuenta lo dicho para las cerámicas ibéricas, los únicos testigos que poseemos hasta el presente de la época romano-republicana en el núcleo urbano de Écija, corresponden a la excavación de la calle Alcázar, 38, donde las estructuras de habitación más recientes se fechan entre los siglos III y I a.C. El resto de la documentación arqueológica para estas fechas se reduce a fragmentos de cerámicas campanienses, en la mayoría de los casos insatisfactoriamente fechadas, cuya área de dispersión coincide grosso modo con la Astigi Vetus citada.

Fig. 17: Situación previa

Fig. 18: Estado actual
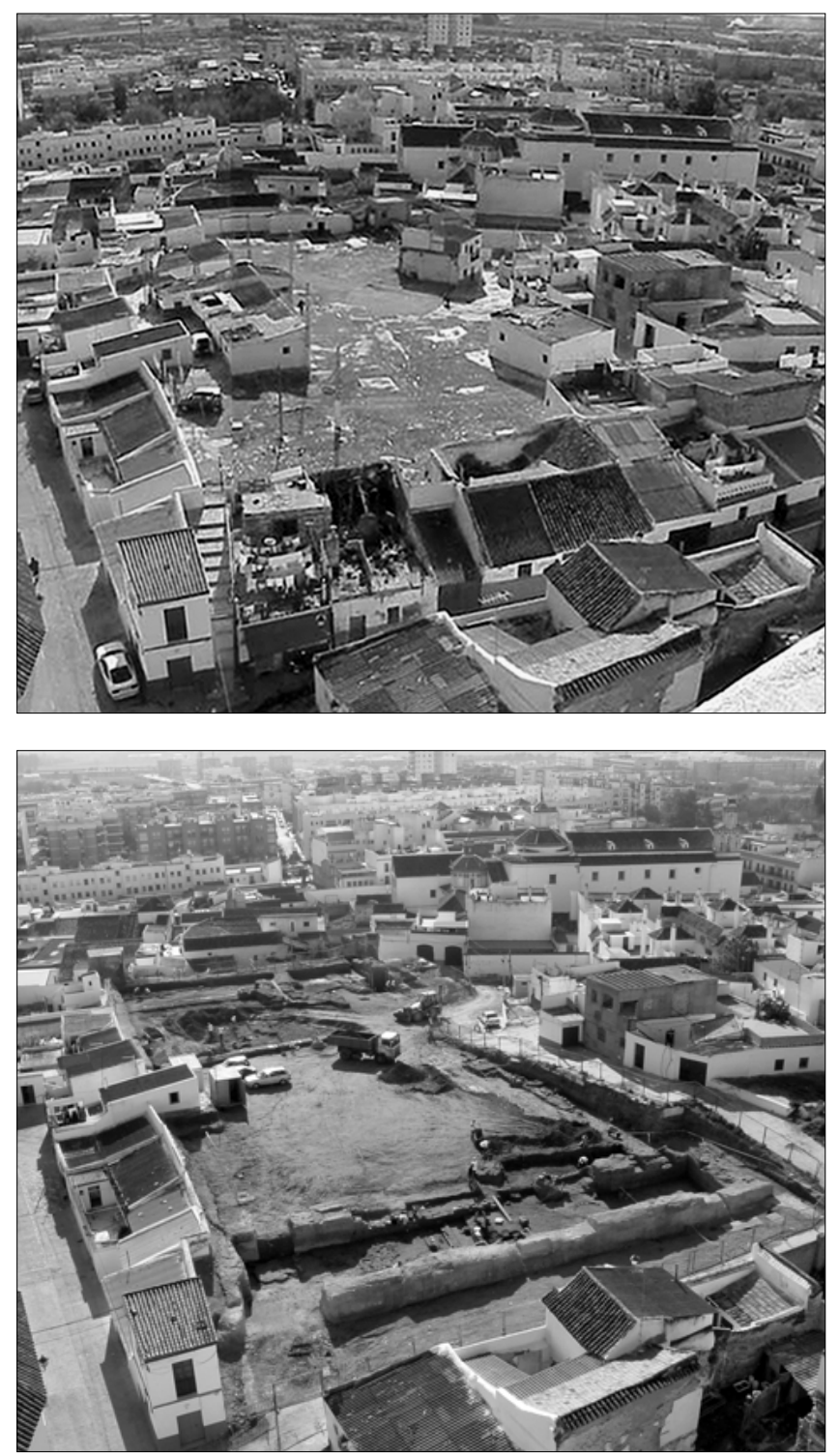
En el año 14 a.C., como fecha generalmente admitida, Augusto funda la Colonia Augusta Firma Astigi en el lugar de la vieja Astigi. Esto supuso un cambio importante en la concepción urbanística de la ciudad, por no decir en este caso nada sobre su paisaje agrario. En primer lugar, hemos de suponer, y así parece deducirse del entramado urbano actual, que se procedió a la expansión de la antigua ciudad sobre la base de la creación de un parcelario urbano ortogonal, según los criterios seguidos en las distintas fundaciones romanas de la época. Los ejes fundamentales de este parcelario vendrían establecidos por dos calles perpendiculares denominadas kardo maximus (con orientación aproximada N-S) y decumanus maximus (con orientación aproximada E-O), ambos documentados arqueológicamente en la ciudad.

Como suele suceder en las ciudades andaluzas es evidente la herencia en el parcelario actual del urbanismo islámico, con las lógicas alteraciones que se han sucedido con el paso del tiempo. Según las fuentes escritas islámicas el recinto urbano romano se mantiene hasta su destrucción en época califal, en el año 9|3, como medida de castigo de Abderramán III contra los ecijanos por su apoyo al rebelde Ibn Hafsun. No hay evidencias de que la cerca se reconstruyera hasta la segunda mitad del siglo XII, en el periodo almohade, cuando se hace presente la amenaza cristiana.

La tipología de la muralla almohade de Écija es la característica de las construcciones defensivas de los imperios norteafricanos: lienzos de cajones de tapial construidos con encofrados de madera (tabiya) con torres de planta rectangular con o sin cámara distribuidas en tramos regulares. Especial atención merece desde el punto de vista poliorcético este recinto del Alcázar, del que quedan escasos restos debido al proceso de degradación urbana al que se ha visto sometida esta parte de la ciudad. En el interior del Alcázar, en su ángulo suroeste se situaba el denominado Castillo de las Siete Torres, del cual se han conservado escasos lienzos, restos de una torre perimetral y parte de la estructura de la Torre del Homenaje.
El 3 de mayo de 1240 tomó Fernando III la ciudad y se instalaron los cristianos en la Calahorra o Alcázar, siguiendo los musulmanes habitando la ciudad y su término bajo la garantía de los tratados como tributarios del rey cristiano hasta que en 1262 Alfonso $X$ el Sabio determinó que la abandonaran en masa, aunque hasta el siglo XVI perduró un núcleo -la Morería - de bastante importancia.

En los siglos posteriores, cuando el Alcázar pierde su función defensiva, la Plaza de Armas se va abandonando paulatinamente, convirtiéndose en un espacio residual dentro de la ciudad, proceso que culmina a partir de la década de los 60, cuando el cerro del "Picadero" se convierte en todo un barrio de infraviviendas.

La Intervención Arqueológica Puntual que se está desarrollando en "el Picadero" desde el pasado mes de noviembre de 200 I tiene un doble objetivo. Desde una perspectiva científica, documentar el trazado de este Castillo y su Plaza de Armas, prácticamente irreconocibles en la actualidad, así como toda la secuencia de ocupación de esta área desde sus orígenes. Patrimonialmente, recuperar para la ciudad este espacio público degradado, en el que todavía se ubican algunas infraviviendas. Entre los primeros resultados que se pueden extraer de la intervención arqueológica, destaca la constatación de un nivel masivo de rellenos modernos y contemporáneos, que llega de momento a los cuatro metros, sin que se haya alcanzado todavía los niveles de ocupación del castillo en época almohade, lo que nos están haciendo revisar incluso la propia existencia de esta hipotética elevación original sobre el valle del Genil, que conforme avanza la excavación más se va configurando como de posible origen antrópico. De este modo, se han preservado en alzado hasta cuatro metros de los lienzos del recinto del castillo y sus compartimentaciones interiores, en unos niveles estratigráficos de los siglos $\mathrm{XV}-\mathrm{XVI}$ en el momento actual.

\section{Notas}

I. La intervención de 1997 fue codirigida por el arqueólogo Juan Manuel Vargas Jiménez: A. Romo, J.M. Vargas, E. Domínguez y M. Ortega "De las termas a la mackbara. Intervención arqueológica en la Plaza de España de Écija (Sevilla)". A.A.A.II'98, 97।-988.

2. En la actualidad, se están ampliando los estudios de la mackbara, con un completo equipo técnico compuesto por los arqueólogos E. Domínguez, A. Fernández, M. Ortega y L. Román; los antropólogos J.M. Guijo, I. López, J.C. Pecero, R. Lacalle y L. Román , así como S. García y M. Fernández para la documentación planmimétrica. Igualmente contamos con el equipo de palinólogos de la Universidad de Córdoba, a cargo del Dr. J.L. Ubera, la Universidad de Huelva para los estudios pétreos, la Autónoma de Barcelona para la investigación sobre elementos traza, el Instituto Nacional de Toxicología de Sevilla para analíticas bioquímicas, etc.

3. Luis A. García Moreno. "La cristianización de la topografía de las ciudades de la Península Ibérica durante la Antigüedad Tardía", Arch. Esp. Arq. 50-5I, (1977-78), 317-319.

4. Julio Navarro Palazón. "El cementerio islámico de San Nicolás de Murcia. Memoria preliminar", I CAME, T. IV. Zaragoza, 1986, 7-37. 